\section{Kidney \\ Blood Pressure Research}

.

\title{
Association of very Low-density Lipoprotein Cholesterol with All-cause and Cardiovascular Mortality in Peritoneal Dialysis
}

\author{
Xishao Xie Xiaohui Zhang Shilong Xiang Xingqun Yan Haojie Huang \\ Yuanshi Tian Zhangfei Shou Jianghua Chen
}

Kidney Disease Center, The First Affiliated Hospital, Medical School of Zhejiang University, Qingchun Rd, Hangzhou, Zhejiang Province, P.R. China

\section{Key Words}

Cardiovascular disease $\bullet$ End-stage kidney disease $•$ Mortality $•$ Peritoneal dialysis

\begin{abstract}
Background/Aims: Cardiovascular disease (CVD) is the leading cause of death in dialysis patients. Little is known about the relationship between very low-density lipoprotein cholesterol (VLDL-C) and cardiovascular mortality in these patients. Methods: A total of 1324 incident patients who began continuous ambulatory peritoneal dialysis (CAPD) therapy at our hospital between January 1, 2005, and September 30, 2014, with baseline serum VLDL-C values were investigated. The associations of the VLDL-C levels with all-cause and cardiovascular mortality were assessed. Results: The mean age of the cohort was $50.2 \pm 14.8$ years, and the mean VLDL-C level was $33.6 \pm 18.0 \mathrm{mg} / \mathrm{dl}$. One hundred sixty-five (12.5\%) patients died during the study period. Multivariable models revealed that the high VLDL-C group was associated with significantly higher all-cause $(\mathrm{HR}, 2.08,95 \% \mathrm{CI}, 1.13$ to $3.29, P=0.002)$ and cardiovascular mortality (HR, 1.92, 95\% CI, 1.18 to $4.29, P=0.013)$ compared with the low VLDL-C group even after adjusting for various covariates. Using the VLDL-C level as a continuous variable, the hazard ratios (HRs) of all-cause and cardiovascular mortality associated with a $10-\mathrm{mg} / \mathrm{dl}$ increase in VLDL-C level were 1.12 (95\% CI, 1.02 to $1.26, P=0.025)$ and 1.11 (95\% CI, 1.02 to $1.22, P=0.029$ ), respectively. VLDL-C was associated more strongly to all-cause (e.g., Akaike information criteria of 1990.205 vs. 1994.451) and cardiovascular (e.g., Akaike information criteria of 984.146 vs. 985.634) mortality than triglyceride (TG) levels. Conclusions: An elevated VLDL-C level is an independent risk factor for all-cause and cardiovascular mortality in peritoneal dialysis (PD) patients.
\end{abstract}




\section{Kidney Blood Pressure Research}

\section{Introduction}

Cardiovascular diseases (CVDs) are recognized as the major cause of mortality in dialysis patients and are responsible for $40 \%$ to $50 \%$ of deaths; this rate is ten to 30 times higher than that in the general population [1-4].

Dyslipidemia is often observed in patients with end-stage renal disease (ESRD) [5] and is characterized by abnormal concentrations and compositions of plasma lipoproteins. Studies in the general population have revealed that reductions in total cholesterol and LDL-C levels are effective in reducing cardiovascular events and mortality [6-8]. Unfortunately, several epidemiological surveys and randomized clinical trials have failed to show a beneficial effect of lipid-lowering therapy in terms of reducing CVD in dialysis patients despite significant reductions in LDL-C levels [9-12]. These findings suggest that the accelerated atherosclerosis and CVD in most dialysis patients may not be due to elevated LDL-C levels. Elevated serum triglyceride (TG) levels are associated with an increased risk of CVD, but this relationship is ambiguous because it becomes attenuated after adjusting for HDL-C and LDL-C [13]. However, recent genetic studies have provided additional evidence in favor of a causal and independent association between triglyceride-rich lipoproteins and CVD [14, 15]. Thus, focus is shifting to alternative measures of TGRL metabolism as potential causal biomarkers of CVD risk [16]. Very low-density lipoprotein (VLDL) is the most atherogenic TGRL particles, and the measurement of VLDL-C is relatively straightforward and captures distinct aspects of the TGRL and serum TG [17]. A large cross-sectional study (Penn Diabetes Heart Study (PDHS)) found that higher VLDL-C levels were associated with increasing coronary artery calcification (CAC) after adjusting for numerous traditional CV risk factors in patients with type 2 diabetes [18].

Peritoneal dialysis treatment may further exacerbate lipoprotein abnormalities, and high levels of VLDL-C may lead the peripheral artery atherosclerosis $[19,20]$. However, it is unclear whether VLDL-C level is an independent risk for mortality in PD patients. Therefore, a longitudinal cohort study was conducted to assess whether the VLDL-C level was useful in predicting the all-cause and cardiovascular mortalities in PD patients.

\section{Materials and Methods}

\section{Study Population}

All incident patients who began CAPD therapy at the First Affiliated Hospital of Zhejiang University in China between January 1, 2005, and September 30, 2014, were investigated. The exclusion criteria were an age below 18 years at the initiation of PD therapy, transfer from hemodialysis therapy or failed kidney transplantation, a follow-up of less than 90 days, and the recovery of renal function. This study was performed in accordance with the Declaration of Helsinki and approved by the Clinical Research Ethics Committee of the First Affiliated Hospital of Zhejiang University. All participants provided informed consent before enrollment.

\section{Data Collection}

Clinical data were collected from our regularly updated computerized records and reviews of the patients' medical and nursing notes. Baseline demographic and clinical data, including gender, age, body mass index (BMI), cause of ESRD, blood pressure, lipid-lowing therapy, prior history of hemodialysis (HD), and comorbid conditions (history of angina, myocardial infarction, cerebrovascular disease, chronic pulmonary disease, diabetes, peripheral vascular disease and malignancy), were collected. The Charlson comorbidity index (CCI) was calculated according to presence of each comorbidity [21]. The collected biochemical data included baseline very low-density lipoprotein cholesterol (VLDL-C), triglycerides, total cholesterol, high-density lipoprotein cholesterol (HDL-C), low-density lipoprotein cholesterol (LDL-C), hemoglobin, serum albumin, uric acid, phosphates, calcium, alkaline phosphatase (ALP), potassium, C-reactive protein and parathyroid hormone. All of the biochemical parameters were assessed in the center 


\section{Kidney \\ Blood Pressure Research}

Xie et al.: VLDL-C in Peritoneal Dialysis

laboratory of our hospital. Specially, VLDL-C was measured as a transformation of cholesterol particle. The dialysis dose (Kt/V) was calculated based on 24-h dialysate collection using PD Adequest software (Baxter Healthcare). Residual renal function was calculated as the mean of the urea and creatinine clearance and adjusted for $1.73 \mathrm{~m}^{2}$ of body surface area from a 24-h urine collection.

The primary outcome of interest was all-cause mortality, and cardiovascular (CV) mortality was considered as the secondary outcome of interest. Cardiovascular death was defined as death caused by acute myocardial infarction, atherosclerotic heart disease, arrhythmia, cardiomyopathy, congestive heart failure, or cerebrovascular events [22] as determined by the PD nurses and professors after comprehensive analyses of the patients' medical records. Survival status was censored on March 31, 2015, for the patients who were still on PD therapy at our center.

\section{Statistical analysis}

The participants were divided into the following 3 groups based on the VLDL-C level tertiles: low (< $24.4 \mathrm{mg} / \mathrm{dl}$ ), middle (22.4-37.5 mg/dl), and high ( $>37.5 \mathrm{mg} / \mathrm{dl})$. The patient characteristics are presented for each group. Continuous variables are presented as the means and the standard deviations or the medians with the interquartile ranges, and categorical variables are presented as frequencies with percentages. Differences between groups were examined with one-way ANOVA, Kruskal-Wallis, or chi-square tests as appropriate. The correlations between VLDL-C and continuous variables were assessed by Pearson's correlation analysis, and categorical variables were evaluated using Spearman's R test. A multiple linear regression model was used to identify the determinants of VLDL-C level.

Survival was analyzed using the Kaplan-Meier method, and the groups were compared using a logrank test. The censored events included kidney transplantation, transfer to hemodialysis therapy, a move to another dialysis center, and loss to follow-up. The Cox proportional hazards regression model was used to assess the relationship between the VLDL-C levels and all-cause and cardiovascular mortalities after adjusting for several groups of covariates. Covariates with $P$-value $<0.2$ in univariate models or for importance of concern were selected for multivariate Cox regression models. A competing risk regression model based on Fine and Gray was also used. The results are expressed as the hazard ratio (HR) and the 95\% confidence interval (95\% CI). Because plasma triglycerides and VLDL-C levels were highly correlated (Pearson $r=0.76$ ), these parameters were not included in models together. To identify whether VLDL-C was associated with mortality independent of plasma triglycerides, we assessed the relationships of VLDL-C with all-cause and cardiovascular mortalities in adjusted models where patients were stratified in to those with high triglycerides ( $>150 \mathrm{mg} / \mathrm{dl}$ ) and low triglycerides ( $<150 \mathrm{mg} / \mathrm{dl})$. We also compared VLDL-C and TG association with mortality in Cox regression models using Akaike information criteria (AIC) and Bayesian information criteria (BIC) [23]. All statistical analyses were performed using SPSS version 19.0 (SPSS Inc.) and SAS version 9.2 (SAS Institute Inc.). $P<0.05$ was considered statistically significant.

\section{Results}

Patient Characteristics

A total of 1529 patients initiated peritoneal dialysis at our center during the study period; 205 patients were excluded, and the remaining 1324 patients were included in the final analysis (Fig. 1). The mean age of the cohort was $50.2 \pm 14.8$ years, $55.7 \%$ of the patients were male, and the mean VLDL-C level was $33.6 \pm 18.0 \mathrm{mg} / \mathrm{dl}$. The baseline characteristics of the patients categorized by VLDL-C tertile are summarized in Table 1 . The patients with higher VLDL-C levels were more likely to be female, exhibited higher prevalence of diabetes mellitus and previous HD, had higher Charlson comorbidity scores and rates of statin use, had higher hemoglobin, calcium, C-reactive protein, total triglycerides, total cholesterol, HDL-C, LDL-C and potassium levels, and had lower serum albumin and parathyroid hormone levels $(P<0.05)$. No significant differences were observed between the groups in terms of age, blood pressure, BMI, education level, residual GFR, total Kt/Vurea, serum uric acid, phosphate or ALP levels. 


\section{Kidney Blood Pressure Research}

Factors associated with baseline VLDL-C levels

The results of correlation analyses are listed in Table 2. There was no correlation between age, residual GFR, serum phosphorus, CRP, total Kt/V urea and VLDL-C level. In contrast, baseline VLDL-C levels positively correlated with sex, Charlson comorbidity index score, BMI, hemoglobin, serum calcium, TG, LDL-C and ALP levels and negatively correlated with serum albumin, HDL-C, potassium and PTH levels. Multivariate linear regression analysis indicated that serum albumin $(\beta=-0.08, p$ $<0.001)$, $\mathrm{TG}(\beta=0.73$, $p<0.001)$, HDL-C $(\beta=$ $-0.24, p<0.001$ ) and LDL-C $(\beta=0.293, \quad p$ $<0.001$ ) levels were independently associated with baseline VLDL-C levels.

Associations of the VLDL-C levels with all-cause and CV mortalities

The median follow-up period was 25.4 months (range from 3.1 to 125.2 months). During the study period, 165 (12.5\%) patients died, $178(13.4 \%)$ patients were transferred to HD, and 261 (19.7\%) patients underwent kidney transplantati-
Table 1. Demographics and biochemical characteristics

\begin{tabular}{|c|c|c|c|c|}
\hline & $\begin{array}{c}\text { Low VLDL } \\
(451)\end{array}$ & $\begin{array}{c}\text { Middle VLDL } \\
(435)\end{array}$ & $\begin{array}{c}\text { High VLDL } \\
(438)\end{array}$ & $P$ \\
\hline VLDL-C (mg/dL) & $17.0 \pm 5.3$ & $30.1 \pm 3.6$ & $53.3 \pm 16.2$ & $<0.001$ \\
\hline Age & $49.2 \pm 13.8$ & $51.4 \pm 14.5$ & $50.1 \pm 14.2$ & 0.06 \\
\hline Male (\%) & $272(60.3)$ & $247(56.8)$ & $219(50.0)$ & 0.007 \\
\hline \multicolumn{5}{|l|}{ Education } \\
\hline Illiteracy and elementary (\%) & $176(39.0)$ & $179(41.1)$ & $175(40.0)$ & \multirow[t]{2}{*}{0.881} \\
\hline Secondary and higher (\%) & $275(61.0)$ & $256(58.9)$ & $263(60)$ & \\
\hline BMI $\left(\mathrm{kg} / \mathrm{m}^{2}\right)$ & $21.4 \pm 7.9$ & $21.5 \pm 3.0$ & $21.8 \pm 3.3$ & 0.524 \\
\hline \multicolumn{5}{|l|}{ Blood pressure } \\
\hline Systolic (mmHg) & $146(136-153)$ & 145(131-156) & $145(135-159)$ & 0.379 \\
\hline Diastolic (mmHg) & $89(81-96)$ & $88(80-96)$ & $89(81-97)$ & 0.723 \\
\hline Diabetes mellitus (\%) & $45(10.0)$ & $70(16.1)$ & $73(16.7)$ & 0.007 \\
\hline Charlson comorbidity score & $3.2 \pm 1.4$ & $3.6 \pm 1.6$ & $3.6 \pm 1.5$ & $<0.001$ \\
\hline \multicolumn{5}{|l|}{ Baseline biochemistry } \\
\hline Hemoglobin (g/dL) & $8.2 \pm 1.6$ & $8.2 \pm 1.7$ & $8.5 \pm 1.7$ & $<0.013$ \\
\hline Albumin $(\mathrm{g} / \mathrm{dL})$ & $3.74 \pm 0.52$ & $3.67 \pm 0.55$ & $3.62 \pm 0.59$ & 0.009 \\
\hline Uric acid (mg/dL) & $8.8 \pm 2.1$ & $8.7 \pm 2.3$ & $8.6 \pm 2.3$ & 0.436 \\
\hline Calcium (mg/dL) & $8.2 \pm 1.1$ & $8.4 \pm 0.9$ & $8.5 \pm 1.0$ & $<0.001$ \\
\hline Phosphate (mg/dL) & $5.7 \pm 1.4$ & $5.6 \pm 1.6$ & $5.7 \pm 1.7$ & 0.549 \\
\hline Triglycerides (mg/dL) & $97.1 \pm 40.0$ & $126.9 \pm 47.6$ & $199.3 \pm 119.8$ & $<0.001$ \\
\hline Total cholesterol (mg/dL) & $96.2 \pm 39.4$ & $127.1 \pm 46.7$ & $200.3 \pm 119.5$ & $<0.001$ \\
\hline $\mathrm{HDL}-\mathrm{C}(\mathrm{mg} / \mathrm{dL})$ & $46.8 \pm 14.3$ & $40.9 \pm 11.2$ & $39.07 \pm 12.3$ & $<0.001$ \\
\hline LDL-C (mg/dL) & $81.3 \pm 27.5$ & $87.9 \pm 23.6$ & $104.7 \pm 36.2$ & $<0.001$ \\
\hline Alkaline phosphatase (U/L) & $76.1 \pm 56.8$ & $76.4 \pm 40.1$ & $77.3 \pm 49.3$ & 0.940 \\
\hline Potassium (mmol/L) & $4.6 \pm 0.8$ & $4.5 \pm 0.7$ & $4.5 \pm 0.7$ & 0.071 \\
\hline Parathyroid hormone $(\mathrm{pg} / \mathrm{mL})$ & $329(192-497)$ & $279(153-437)$ & $294(146-449)$ & $<0.009$ \\
\hline C-reactive protein & $2.4(1.2-6.1)$ & $2.6(1.3-8.6)$ & $2.7(1.1-8.9)$ & 0.048 \\
\hline Residual GFR (mL/min/1.73 m²) & $6.8(5.1-8.6)$ & $7.0(5.2-8.6)$ & $6.8(5.0-8.7)$ & 0.865 \\
\hline Lipid-lowing therapy (\%) & $23(5.1)$ & $49(11.3)$ & $67(10.5)$ & $<0.001$ \\
\hline \multicolumn{5}{|c|}{$\begin{array}{l}\text { Abbreviations: VLDL-C, very low-density lipoprotein cholesterol; HDL-C, high-density } \\
\text { lipoprotein cholesterol; LDL-C, low-density lipoprotein; residual GFR, residual glomerular } \\
\text { filtration rate; BMI, body mass index. }\end{array}$} \\
\hline
\end{tabular}

1529 incident patients start PD at our center $(2005 / 1 / 1-2014 / 9 / 31)$

xcluded $(n=205)$

Did not meet inclusion criteria $(n=194)$

Without available data $(\mathrm{n}=11)$

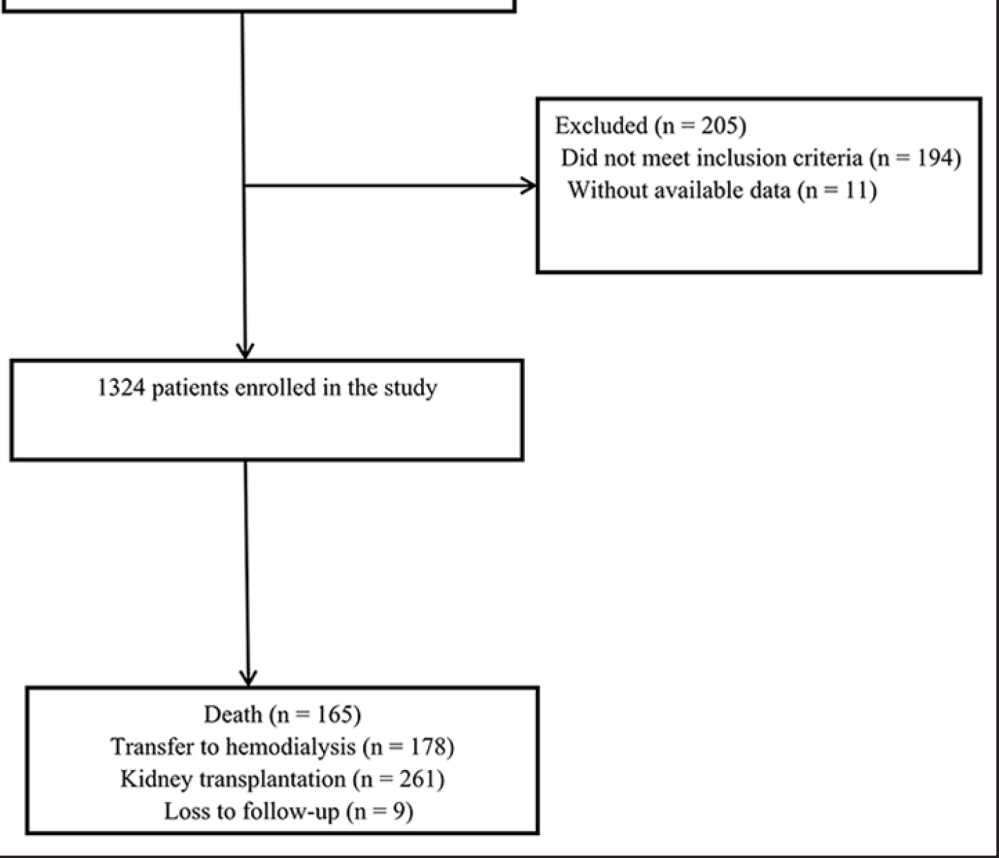

Fig. 1. Flow chart of the participants in the study cohort. PD, peritoneal dialysis. 


\section{Kidney \\ Blood Pressure \\ Research}

Table 2. Correlation analysis between VLDL-C level and patient characteristics

\begin{tabular}{|c|c|c|c|c|c|c|c|c|c|c|c|c|c|c|c|c|c|}
\hline & VLDL & Age & Sex & $\mathrm{CCI}$ & BMI & GFR & UA & $\mathrm{Ca}$ & $\mathrm{P}$ & Albumin & $\mathrm{TG}$ & CRP & HDL & LDL & $\mathrm{Hb}$ & $\mathrm{K}$ & ALP \\
\hline Age & 0.03 & & & & & & & & & & & & & & & & \\
\hline Sex & $0.10^{\mathrm{b}}$ & 0.01 & & & & & & & & & & & & & & & \\
\hline $\mathrm{CCI}$ & $0.10^{\mathrm{b}}$ & $0.82^{\mathrm{b}}$ & -0.01 & & & & & & & & & & & & & & \\
\hline BMI & $0.12^{\mathrm{b}}$ & $0.14^{\mathrm{b}}$ & $-0.19 b$ & $0.10^{\mathrm{b}}$ & & & & & & & & & & & & & \\
\hline GFR & -0.01 & $0.15^{b}$ & $-0.22^{b}$ & $0.19^{b}$ & 0.03 & & & & & & & & & & & & \\
\hline $\mathrm{UA}$ & -0.04 & $-0.17^{b}$ & $-0.18^{b}$ & $-0.19 \mathrm{~b}$ & 0.05 & $-0.08^{a}$ & & & & & & & & & & & \\
\hline $\mathrm{Ca}$ & $0.11^{\mathrm{b}}$ & 0.01 & $0.13^{\mathrm{b}}$ & 0.02 & -0.002 & $0.17^{\mathrm{b}}$ & -0.07 & & & & & & & & & & \\
\hline P & 0.001 & $-0.24^{\mathrm{b}}$ & -0.05 & $-0.24^{b}$ & 0.02 & $-0.48^{b}$ & $0.20^{\mathrm{b}}$ & $-0.29 b$ & & & & & & & & & \\
\hline Albumin & $-0.08^{a}$ & $-0.10^{b}$ & $0.08^{\mathrm{b}}$ & $-0.19^{b}$ & 0.02 & -0.05 & 0.03 & $-0.30^{\mathrm{b}}$ & 0.03 & & & & & & & & \\
\hline TG & $0.73^{\mathrm{b}}$ & -0.004 & $0.17^{\mathrm{b}}$ & 0.05 & $0.17^{\mathrm{b}}$ & -0.01 & $-0.06^{a}$ & $0.19^{\mathrm{b}}$ & -0.04 & 0.05 & & & & & & & \\
\hline CRP & 0.05 & $0.13^{\mathrm{b}}$ & $-0.15^{b}$ & $0.12^{\mathrm{b}}$ & -0.001 & 0.01 & 0.06 & -0.02 & -0.001 & $-0.15^{b}$ & 0.003 & & & & & & \\
\hline HDL & $-0.28^{b}$ & -0.02 & $0.22^{\mathrm{b}}$ & -0.04 & $-0.22^{b}$ & -0.002 & $-0.09 \mathrm{~b}$ & 0.03 & -0.03 & $0.08^{\mathrm{b}}$ & $-0.21^{b}$ & $-0.10^{b}$ & & & & & \\
\hline LDL & $0.34^{\mathrm{b}}$ & -0.02 & $0.15^{\mathrm{b}}$ & 0.03 & $0.07^{b}$ & -0.04 & $-0.08^{b}$ & 0.04 & $0.07^{\mathrm{b}}$ & $-0.09 \mathrm{~b}$ & $0.33 \mathrm{~b}$ & -0.01 & $0.25^{\mathrm{b}}$ & & & & \\
\hline $\mathrm{Hb}$ & $0.09 \mathrm{~b}$ & $0.10^{\mathrm{b}}$ & $-0.11^{b}$ & $0.06^{\mathrm{a}}$ & $0.12 \mathrm{~b}$ & $-0.23^{b}$ & -0.03 & $0.29 \mathrm{~b}$ & $-0.17 b$ & $0.21^{\mathrm{b}}$ & $0.14^{\mathrm{b}}$ & $-0.09 b$ & -0.01 & $0.14^{b}$ & & & \\
\hline K & $-0.06^{a}$ & $-0.06^{a}$ & -0.04 & -0.05 & 0.03 & $-0.11^{b}$ & -0.02 & 0.02 & $0.19^{\mathrm{b}}$ & $0.07^{\mathrm{b}}$ & $-0.06^{\mathrm{a}}$ & -0.03 & 0.004 & 0.05 & -0.01 & & \\
\hline ALP & $0.05^{a}$ & $0.18^{\mathrm{b}}$ & 0.03 & $0.15^{\mathrm{b}}$ & -0.05 & -0.01 & -0.05 & $-0.12^{b}$ & $-0.07^{a}$ & $0.10^{\mathrm{b}}$ & 0.02 & $0.07^{a}$ & 0.02 & 0.01 & 0.03 & 0.02 & \\
\hline PTH & $-0.09^{b}$ & -0.13 & $0.14^{\mathrm{b}}$ & $-0.18^{b}$ & $-0.06^{a}$ & $-0.29 b$ & $0.08^{\mathrm{b}}$ & $-0.32^{\mathrm{b}}$ & $0.24^{\mathrm{b}}$ & $0.11^{\mathrm{b}}$ & $-0.11^{b}$ & 0.03 & 0.04 & $-0.10^{\mathrm{b}}$ & $-0.22^{\mathrm{b}}$ & 0.01 & $0.33^{\mathrm{b}}$ \\
\hline
\end{tabular}

on. Among the 165 deaths, 42 deaths (20 due to CV events) occurred in the lowest tertile group, whereas 49 (24 due to CV events) and 74 (40 due to $\mathrm{CV}$ events) deaths occurred in the middle and highest tertiles, respectively.

The Kaplan-Meier survival curves for all-cause and CV mortalities for the patients with the different VLDL-C levels are illustrated in Fig. 2. All-cause and CVD mortalities vary significantly between the three groups (long-rank test $P<0.001$ ). The patients in the high VLDL-C group exhibited the lowest patient and cardiovascular survival rates.

Table 3 displays the hazard ratios (HRs) of all-cause and cardiovascular mortality that were associated with the different VLDL-C levels while considering the low VLDL-C group as the reference. According to the multivariable Cox proportional hazards model

Fig. 2. Kaplan-Meier survival curves for the patients with different VLDL-C levels. The cumulative mortality curves for (A) all-cause mortality and (B) CV mortality based on the VLDL-C level tertiles at baseline are shown.

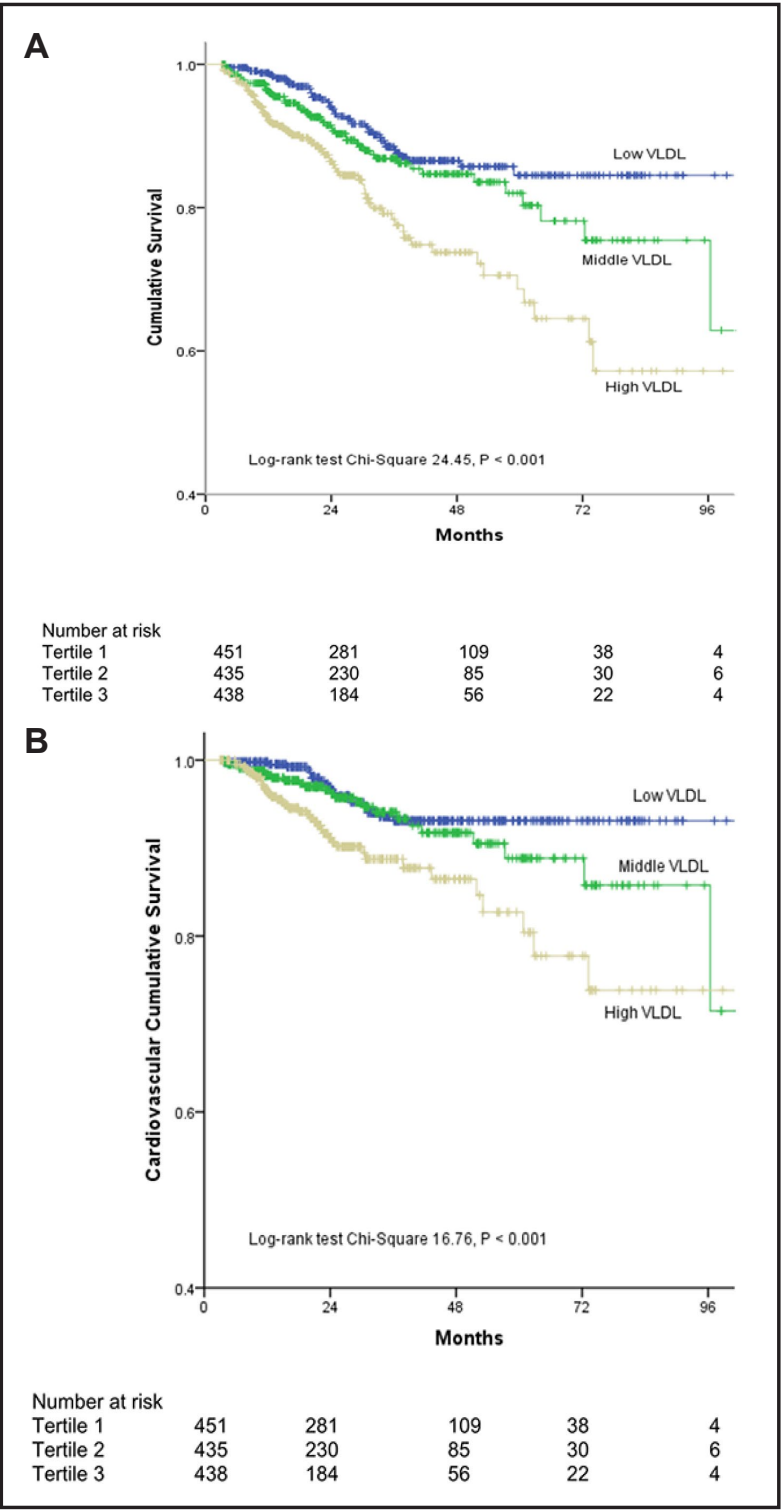




\section{Kidney Blood Pressure Research}

Table 3. Relationships between the tertiles, continuous VLDL-C and all-cause and $\mathrm{CV}$ mortalities

\begin{tabular}{|c|c|c|c|c|c|c|}
\hline & \multicolumn{2}{|l|}{ Tertile 2} & \multicolumn{2}{|l|}{ Tertile 3} & \multicolumn{2}{|c|}{ Continuous VLDL-C } \\
\hline & HR $(95 \% \mathrm{CI})$ & $P$ Value & $\mathrm{HR}(95 \% \mathrm{CI})$ & $P$ Value & HR (95\% CI) & $P$ Value \\
\hline \multicolumn{7}{|c|}{ All-cause mortality } \\
\hline Model 1 & $1.42(0.94-2.13)$ & 0.101 & $2.46(1.68-3.60)$ & $<0.001$ & $1.17(1.10-1.25)$ & $<0.001$ \\
\hline Model 2 & $1.16(0.77-1.77)$ & 0.476 & $2.07(1.40-3.06)$ & $<0.001$ & $1.13(1.05-1.21)$ & 0.001 \\
\hline Model 3 & $1.08(0.71-1.64)$ & 0.73 & $2.02(1.36-2.99)$ & $<0.001$ & $1.11(1.03-1.19)$ & 0.004 \\
\hline Model 4 & $1.12(0.73-1.72)$ & 0.611 & $2.08(1.13-3.29)$ & 0.002 & $1.12(1.02-1.26)$ & 0.025 \\
\hline \multicolumn{7}{|c|}{ CV mortality } \\
\hline Model 1 & $1.46(0.80-2.64)$ & 0.214 & $2.03(1.64-4.81)$ & $<0.001$ & $1.15(1.09-1.26)$ & $<0.001$ \\
\hline Model 2 & $1.14(0.63-2.01)$ & 0.67 & $1.99(1.22-3.64)$ & 0.008 & $1.13(1.07-1.24)$ & 0.006 \\
\hline Model 3 & $1.11(0.60-2.05)$ & 0.74 & $1.97(1.26-3.80)$ & 0.006 & $1.13(1.03-1.24)$ & 0.008 \\
\hline Model 4 & $1.20(0.64-2.24)$ & 0.57 & $1.92(1.18-4.29)$ & 0.013 & $1.11(1.02-1.22)$ & 0.029 \\
\hline \multicolumn{7}{|c|}{$\begin{array}{l}\text { Note: The reference group was the VLDL-C tertile } 1 \text { group. Abbreviations: CI, confidence } \\
\text { interval; CV, cardiovascular; HR, hazard ratio; VLDL-C, very low-density lipoprotein cholesterol. } \\
\text { Model 1, Unadjusted. Model 2. Adjusted for age, gender, education level and Charlson } \\
\text { comorbidity score. Model 3. Adjusted for the model } 2 \text { covariates and hemoglobin, serum } \\
\text { albumin, uric acid, alkaline phosphatase, C-reactive protein, residual glomerular filtration rate. } \\
\text { Model 4. Adjusted for the model } 3 \text { covariates plus high-density lipoprotein cholesterol, } \\
\text { low-density lipoprotein cholesterol and lipid-lowing therapy. }\end{array}$} \\
\hline
\end{tabular}

analysis, the high VLDL-C group was associated with significantly higher allcause (Model 4; HR, 2.08, $95 \% \mathrm{CI}, 1.13$ to $3.29, P=$ 0.002 ) and CV mortality compared with the low VLDL-C group even after adjusting for various covariates (Model 4; HR, $1.92,95 \% \mathrm{CI}, 1.18$ to $4.29, P$ $=0.013$ ). Using the VLDL-C level as a continuous variable, the HRs for allcause and cardiovascular mortalities associated with a $10-\mathrm{mg} / \mathrm{dl}$ increase in the VLDL-C level were 1.12 (95\% CI, 1.02 to $1.26, P=$ $0.025)$ and 1.11 (95\% CI, 1.02 to $1.22, P=0.029$ ), respectively.

Because VLDL-C and TG values were highly correlated (Pearson $r=$ 0.76), their inclusion in Cox models together can
Table 4. Comparation of VLDL-C and TG association with mortality in Cox models using AIC and BIC

\begin{tabular}{lcccc}
\hline & \multicolumn{2}{c}{ All-cause mortality } & \multicolumn{2}{c}{ CV mortality } \\
\cline { 2 - 5 } & VLDL-C & TG & VLDL-C & TG \\
\hline AIC & 1990.205 & 1994.451 & 984.146 & 985.634 \\
BIC & 1989.850 & 1994.054 & 983.701 & 985.147 \\
\hline
\end{tabular}

Model includes age, gender, education level, Charlson comorbidity score, hemoglobin, serum albumin, uric acid, alkaline phosphatase, C-reactive protein, residual glomerular filtration rate, high-density lipoprotein cholesterol, low-density lipoprotein cholesterol and lipid-lowing therapy. Abbreviations: AIC, Akaike information criteria; BIC, Bayesian information criteria; CV, cardiovascular; HR, hazard ratio; VLDL-C, very low-density lipoprotein cholesterol; TG, triglycerides.

Table 5. Association of VLDL-C with mortality stratified by TG levels

\begin{tabular}{|c|c|c|c|c|}
\hline & \multicolumn{2}{|c|}{ All-cause mortality } & \multicolumn{2}{|c|}{ CV mortality } \\
\hline & HR $(95 \% \mathrm{CI})$ & $P$ Value & $\mathrm{HR}(95 \% \mathrm{CI})$ & $P$ Value \\
\hline $\mathrm{TG}>150 \mathrm{mg} / \mathrm{dl}$ & $1.21(1.04-1.42)$ & 0.015 & $1.29(1.04-1.59)$ & 0.018 \\
\hline $\mathrm{TG}<150 \mathrm{mg} / \mathrm{dl}$ & $1.10(1.01-1.22)$ & 0.043 & $1.09(0.96-1.25)$ & 0.17 \\
\hline $\begin{array}{l}\text { Model includes } \\
\text { hemoglobin, se } \\
\text { protein, residu } \\
\text { cholesterol, low } \\
\text { Abbreviations: } \\
\text { VLDL-C, very lov }\end{array}$ & $\begin{array}{l}\text { onfidence inter } \\
\text { ensity lipoprote }\end{array}$ & n level, & arlson comorbid & $\begin{array}{l}\text { score, } \\
\text { eactive }\end{array}$ \\
\hline
\end{tabular}

lead to excess colinearity and potential spurious results. Thus, we compare VLDL-C and TG association with all-cause and CV mortality in Cox models using AIC and BIC scores. The result showed that both AIC and BIC scores were consistently lower for VLDL-C (Table 4). This indicated that VLDL-C performed better than TG in predicting all-cause and CV mortality when other confounders were held equal. Furthermore, stratified analysis also showed that VLDL-C had stronger association with all-cause and CV mortality in patients with TG $>150$ $\mathrm{mg} / \mathrm{dl}$ than those with $\mathrm{TG}<150 \mathrm{mg} / \mathrm{dl}$ (Table 5). 


\section{Kidney Blood Pressure Research}

Xie et al.: VLDL-C in Peritoneal Dialysis

\section{Discussion}

To our knowledge, no prior studies have examined the relationship between serum VLDL-C level and mortality in PD patients. In this retrospective study, we demonstrated that higher VLDL-C levels were associated with higher all-cause and cardiovascular mortalities even after adjusting for several potential confounders (e.g., demographic characteristics, the Charlson comorbidity score, and laboratory parameters). VLDL-C levels associated with higher mortality risk in patients with high TG levels suggesting possible potential value for VLDL-C in risk prediction beyond serum TG.

Epidemiological and genomic studies have suggested that TGRLs are causally relevant to atherosclerotic CVD [14, 15, 24-26]. The results from a large study that included 73,513 participants revealed that a $1 \mathrm{mmol} / \mathrm{l}(39 \mathrm{mg} / \mathrm{dl})$ increase in TGRL was associated with a 2.8 fold increase in the causal risk for ischemic heart disease independent of reduced HDL-C [16]. Takeichi et al [27] and Kugiyama et al [28] also found that elevated TGRL levels are associated with increased risks of CVD. VLDLs are the major component and atherogenic particles of TGRL in the circulation. A PDHS study that examined VLDL-C as an alternative marker of TGRL demonstrated that VLDL-C levels are positively associated with increased coronary artery calcification in patients with type 2 diabetes even after adjusting for traditional risk factors [18]. Laakso et al. also reported that higher VLDL-C levels are associated with an increased risk of CVD in diabetic patients [29]. In dialysis, Kanda et al reported that VLDL-C is associated with peripheral artery disease (diagnosed using the ankle-brachial index) in PD patients with controlled LDL-C levels [20]. In the present study, similar results were observed; we found that elevated VLDL-C levels were associated with increased risks of allcause and CV mortalities in patients treated with peritoneal dialysis independent of HDL-C, LDL-C and triglyceride levels.

Several mechanisms have been proposed to explain why VLDL may be causally related to progression of atherosclerosis and CVD. VLDL is synthesized in the liver and serves as a vehicle that is responsible for the redistribution of triglycerides from liver to the peripheral tissues. Each VLDL particle contains a single molecule of apolipoprotein B100 and has a hydrophobic core that consists primarily of triglycerides and a small amount of cholesterol esters [30, 31]. The sizes of the VLDL particles vary depending on the quantity of triglycerides carried in the particle. Large VLDL particles are secreted from patients with hypertriglyceridemia and may contain 5 to 20 times more cholesterol than LDL. Unlike LDL, VLDL remnants rapidly penetrate the arterial wall, increase endothelial inflammation and facilitate the infiltration of monocytes, which results in foam cell formation and atherosclerosis [32, 33]. Normally, VLDL particles are hydrolyzed by lipoprotein lipase (LPL) and hepatic lipase (HL) in the plasma. Eisenberg et al and Mekki et al reported that the activities of LPL and HL are strongly decreased in patients with nephrotic syndrome and chronic renal failure, which results in hypertriglyceridemia and impaired clearance of the atherogenic, cholesterolenriched remnants of VLDLs, which can rapidly penetrate the arterial wall and contribute cholesterol to atherosclerotic lesions [34-36]. Additionally, VLDL plays an important role in myocardial energetic and function by acting as a metabolic substrate. VLDL is taken up by both LPL and VLDL receptors in the myocardium [30]. Perman et al. demonstrated that hypoxia and ischemia up-regulate the expression of the VLDL receptor in an animal model, which leads to lipid accumulation in the myocardium and an increased risk of mortality following myocardial infarction [37]. Hepatic VLDL overproduction has been reported to be related to insulin resistance [38]. Adiels et al [39] and Gill et al [40] reported that in patients with metabolic syndrome or type 2 diabetes, insulin-resistant states and the loss of insulinmediated suppression of apoB100 secretion lead to increased production of large VLDL-1 particles. Hypersecretion of large VLDL-1 particles, which contain more cholesterol, results in higher levels of remnant particles and small dense LDLs and lower levels of HDL that may contribute to the progression of vascular endothelial injury and atherosclerosis [41-43]. In peritoneal dialysis, glucose absorption and protein loss from the dialysate further aggravate 


\section{Kidney Blood Pressure Research}

the metabolic abnormalities and insulin resistance. Prinsen et al reported that the VLDL-1 apoB100 pool size is increased in PD patients due to increased VLDL-1 apoB100 synthesis in combination with reduced VLDL-1 apoB100 catabolism, which inevitably results in the formation of atherogenic small dense LDL particles that may contribute to the progression of atherosclerosis [19]. Thus, the potential mechanisms mentioned above may contribute to the associations between elevated VLDL-C levels and the increases in all-cause and CV mortalities. VLDL-C is thus potentially a novel therapeutic target in dialysis patients. Our study further revealed that higher VLDL levels were associated with higher all-cause and cardiovascular mortalities in PD patients.

Our study has several limitations. First, it was a retrospective study performed in a single center; therefore, our findings only reveal associations and not causation due to the observational nature of the study. Second, only baseline data were used in our analysis. We did not investigate the influence of changes in VLDL-C levels during the observation period on the mortality of PD patients. Third, only PD patients were included in our study; thus, no extrapolation is possible to patients on hemodialysis or non-dialysis-dependent CKD patients. Despite its limitations, the present study is the first to investigate the association of VLDL-C with mortality in dialysis patients. The relationship between the VLDL-C level and mortality was examined using both a traditional Cox regression model and a competing-risk regression model, and our results were robust to adjustments for multiple risk factors and potential confounders.

\section{Conclusion}

Our study revealed that elevated VLDL-C levels are independently associated with higher risks of all-cause and cardiovascular mortalities in peritoneal dialysis patients. Further studies are needed to identify the underling mechanisms and investigate whether VLDL can serve as a potential new therapeutic target for improving the survival of PD patients with dyslipidemia.

\section{Disclosure Statement}

The authors of this manuscript state that they do not have any conflict of interests and nothing to disclose.

\section{Acknowledgements}

We thank Duo Lv for her assistance with the statistical analysis. This study was supported by the National Natural Science Foundation of China (No. 81170707).

\section{References}

$>1$ Jha V, Garcia-Garcia G, Iseki K, Li Z, Naicker S, Plattner B, Saran R, Wang AY, Yang CW: Chronic kidney disease: Global dimension and perspectives. Lancet 2013;382:260-272.

-2 Herzog CA, Asinger RW, Berger AK, Charytan DM, Diez J, Hart RG, Eckardt KU, Kasiske BL, McCullough PA, Passman RS, DeLoach SS, Pun PH, Ritz E: Cardiovascular disease in chronic kidney disease. A clinical update from kidney disease: Improving global outcomes (kdigo). Kidney Int 2011;80:572-586.

-3 Go AS, Chertow GM, Fan D, McCulloch CE, Hsu CY: Chronic kidney disease and the risks of death, cardiovascular events, and hospitalization. N Engl J Med 2004;351:1296-1305. 


\section{Kidney \\ Blood Pressure Research}

\begin{tabular}{|c|c|}
\hline Kidney Blood Press Res 20 & 2:52-61 \\
\hline $\begin{array}{l}\text { DOI: } 10.1159 / 000469714 \\
\text { Published onlIne: Tharch } 17,2017\end{array}$ & $\begin{array}{l}\text { (c) } 2017 \text { The Author(s). Published by S. Karger AG, Basel } \\
\text { www.karger.com/kbr }\end{array}$ \\
\hline
\end{tabular}

Xie et al.: VLDL-C in Peritoneal Dialysis

4 Tong J, Liu M, Li H, Luo Z, Zhong X, Huang J, Liu R, He F, Fu J: Mortality and Associated Risk Factors in Dialysis Patients with Cardiovascular Disease. Kidney Blood Press Res 2016;41:479-487.

5 Qunibi WY: Dyslipidemia in dialysis patients. Semin Dial 2015;28:345-353.

6 Stone NJ, Robinson JG, Lichtenstein AH, Bairey Merz CN, Blum CB, Eckel RH, Goldberg AC, Gordon D, Levy D, Lloyd-Jones DM, McBride P, Schwartz JS, Shero ST, Smith SC, Jr., Watson K, Wilson PW: 2013 acc/aha guideline on the treatment of blood cholesterol to reduce atherosclerotic cardiovascular risk in adults: A report of the american college of cardiology/american heart association task force on practice guidelines. J Am Coll Cardiol 2014;63:2889-2934.

7 LaRosa JC, Grundy SM, Waters DD, Shear C, Barter P, Fruchart JC, Gotto AM, Greten H, Kastelein JJ, Shepherd J, Wenger NK, Treating to New Targets (TNT) Investigators: Intensive lipid lowering with atorvastatin in patients with stable coronary disease. N Engl J Med 2005;352:1425-1435.

8 Heart Protection Study Collaborative G: Mrc/bhf heart protection study of cholesterol lowering with simvastatin in 20,536 high-risk individuals: A randomised placebo-controlled trial. Lancet 2002;360:7-22.

-9 Bowden RG, La Bounty P, Shelmadine B, Beaujean AA, Wilson RL, Hebert S: Reverse epidemiology of lipiddeath associations in a cohort of end-stage renal disease patients. Nephron Clin Pract 2011;119:c214-219.

10 Baigent C, Landray MJ, Reith C, Emberson J, Wheeler DC, Tomson C, Wanner C, Krane V, Cass A, Craig J, Neal B, Jiang LX, Hooi LS, Collins R, et al.: The effects of lowering LDL cholesterol with simvastatin plus ezetimibe in patients with chronic kidney disease (Study of Heart and Renal Protection): a randomised placebo-controlled trial. Lancet 2011;377:2181-2192.

11 Fellstrom BC, Jardine AG, Schmieder RE, Holdaas H, Bannister K, Beutler J, Chae DW, Chevaile A, Cobbe SM, Gronhagen-Riska C, Wuthrich RP, Gottlow M, Johnsson E, Zannad F, Grp AS: Rosuvastatin and cardiovascular events in patients undergoing hemodialysis. New Engl J Med 2009;360:1395-1407.

12 Wanner C, Krane V, März W, Olschewski M, Mann JF, Ruf G, Ritz E, German Diabetes and Dialysis Study Investigators: Atorvastatin in patients with type 2 diabetes mellitus undergoing hemodialysis. New Engl J Med 2005;353:238-248.

-13 Emerging Risk Factors C, Di Angelantonio E, Sarwar N, Perry P, Kaptoge S, Ray KK, Thompson A, Wood AM, Lewington S, Sattar N, Packard CJ, Collins R, Thompson SG, Danesh J: Major lipids, apolipoproteins, and risk of vascular disease. JAMA 2009;302:1993-2000.

14 Do R, Willer CJ, Schmidt EM, Sengupta S, Gao C, Peloso GM, Gustafsson S, Kanoni S, Ganna A, Chen J, Buchkovich ML, Mora S, Beckmann JS, Bragg-Gresham JL, Chang HY, et al. : Common variants associated with plasma triglycerides and risk for coronary artery disease. Nat Genet 2013;45:1345-1352.

15 Triglyceride Coronary Disease Genetics C, Emerging Risk Factors C, Sarwar N, Sandhu MS, Ricketts SL, Butterworth AS, Di Angelantonio E, Boekholdt SM, Ouwehand W, Watkins H, et al. : Triglyceride-mediated pathways and coronary disease: Collaborative analysis of 101 studies. Lancet 2010;375:1634-1639.

16 Varbo A, Benn M, Tybjaerg-Hansen A, Jorgensen AB, Frikke-Schmidt R, Nordestgaard BG: Remnant cholesterol as a causal risk factor for ischemic heart disease. J Am Coll Cardiol 2013;61:427-436.

17 Jialal I, Devaraj S: Remnant lipoproteins: Measurement and clinical significance. Clin Chem 2002;48:217219.

18 Prenner SB, Mulvey CK, Ferguson JF, Rickels MR, Bhatt AB, Reilly MP: Very low density lipoprotein cholesterol associates with coronary artery calcification in type 2 diabetes beyond circulating levels of triglycerides. Atherosclerosis 2014;236:244-250.

19 Prinsen BH, Rabelink TJ, Romijn JA, Bisschop PH, de Barse MM, de Boer J, van Haeften TW, Barrett PH, Berger R, de Sain-van der Velden MG: A broad-based metabolic approach to study VLDL apoB100 metabolism in patients with ESRD and patients treated with peritoneal dialysis. Kidney Int 2004;65:10641075.

20 Kanda E, Ai M, Okazaki M, Maeda Y, Sasaki S, Yoshida M: The association of very-low-density lipoprotein with ankle-brachial index in peritoneal dialysis patients with controlled serum low-density lipoprotein cholesterol level. BMC Nephrol 2013;14:212.

-21 Charlson ME, Pompei P, Ales KL, MacKenzie CR: A new method of classifying prognostic comorbidity in longitudinal studies: Development and validation. J Chronic Dis 1987;40:373-383.

-22 Delmez JA, Yan G, Bailey J, Beck GJ, Beddhu S, Cheung AK, Kaysen GA, Levey AS, Sarnak MJ, Schwab SJ, Hemodialysis Study G: Cerebrovascular disease in maintenance hemodialysis patients: Results of the hemo study. Am J Kidney Dis 2006;47:131-138. 


\section{Kidney \\ Blood Pressure Research}

23 Akaike H: A new look at the statistical model identification. IEE Trans Automatic Control 1999;19:716723.

24 Rosenson RS, Davidson MH, Hirsh BJ, Kathiresan S, Gaudet D: Genetics and causality of triglyceride-rich lipoproteins in atherosclerotic cardiovascular disease. J Am Coll Cardiol 2014;64:2525-2540.

25 Global Lipids Genetics C, Willer CJ, Schmidt EM, Sengupta S, Peloso GM, Gustafsson S, Kanoni S, Ganna A, Chen J, Buchkovich ML, Mora S, Beckmann JS, Bragg-Gresham JL, Chang HY, Demirkan A: Discovery and refinement of loci associated with lipid levels. Nat Genet 2013;45:1274-1283.

-26 Sarwar N, Danesh J, Eiriksdottir G, Sigurdsson G, Wareham N, Bingham S, Boekholdt SM, Khaw KT, Gudnason V: Triglycerides and the risk of coronary heart disease: 10,158 incident cases among 262,525 participants in 29 western prospective studies. Circulation 2007;115:450-458.

27 Takeichi S, Yukawa N, Nakajima Y, Osawa M, Saito T, Seto Y, Nakano T, Saniabadi AR, Adachi M, Wang T, Nakajima K: Association of plasma triglyceride-rich lipoprotein remnants with coronary atherosclerosis in cases of sudden cardiac death. Atherosclerosis 1999;142:309-315.

-28 Kugiyama K, Doi H, Takazoe K, Kawano H, Soejima H, Mizuno Y, Tsunoda R, Sakamoto T, Nakano T, Nakajima K, Ogawa H, Sugiyama S, Yoshimura M, Yasue H: Remnant lipoprotein levels in fasting serum predict coronary events in patients with coronary artery disease. Circulation 1999;99:2858-2860.

-29 Laakso M, Lehto S, Penttila I, Pyorala K: Lipids and lipoproteins predicting coronary heart disease mortality and morbidity in patients with non-insulin-dependent diabetes. Circulation 1993;88:1421-1430.

-30 Niu YG, Evans RD: Very-low-density lipoprotein: Complex particles in cardiac energy metabolism. J Lipids 2011;2011:189876.

-31 McEneny J, O'Kane MJ, Moles KW, McMaster C, McMaster D, Mercer C, Trimble ER, Young IS: Very low density lipoprotein subfractions in type ii diabetes mellitus: Alterations in composition and susceptibility to oxidation. Diabetologia 2000;43:485-493.

-32 Nakajima K, Nakano T, Tanaka A: The oxidative modification hypothesis of atherosclerosis: The comparison of atherogenic effects on oxidized ldl and remnant lipoproteins in plasma. Clin Chim Acta 2006;367:36-47.

33 Nakamura T, Takano H, Umetani K, Kawabata K, Obata JE, Kitta Y, Kodama Y, Mende A, Ichigi Y, Fujioka D, Saito Y, Kugiyama K: Remnant lipoproteinemia is a risk factor for endothelial vasomotor dysfunction and coronary artery disease in metabolic syndrome. Atherosclerosis 2005;181:321-327.

-34 Mekki K, Prost J, Remaoun M, Belleville J, Bouchenak M: Long term hemodialysis aggravates lipolytic activity reduction and very low density, low density lipoproteins composition in chronic renal failure patients. BMC Cardiovasc Disord 2009;9:41.

-35 Mekki K, Prost J, Bouchenak M, Remaoun M, Belleville J: Plasma lipoprotein lipase, hepatic lipase activities, vldl, ldl compositions at different times of hemodialysis. Atherosclerosis 2003;169:269-277.

36 Sato T, Liang K, Vaziri ND: Down-regulation of lipoprotein lipase and vldl receptor in rats with focal glomerulosclerosis. Kidney Int 2002;61:157-162.

37 Perman JC, Boström P, Lindbom M, Lidberg U, StÅhlman M, Hägg D, Lindskog H, Scharin Täng M, Omerovic E, Mattsson Hultén L, Jeppsson A, Petursson P, Herlitz J, Olivecrona G, Strickland DK, Ekroos K, Olofsson SO, Borén J: The VLDL receptor promotes lipotoxicity and increases mortality in mice following an acute myocardial infarction. J Clin Invest 2011;121:2625-2640.

-38 Sparks JD, Sparks CE, Adeli K: Selective hepatic insulin resistance, VLDL overproduction, and hypertriglyceridemia. Arterioscler Thromb Vasc Biol 2012;32:2104-2112.

39 Adiels M, Olofsson SO, Taskinen MR, Boren J: Overproduction of very low-density lipoproteins is the hallmark of the dyslipidemia in the metabolic syndrome. Arterioscler Thromb Vasc Biol 2008;28:12251236.

40 Gill JM, Brown JC, Bedford D, Wright DM, Cooney J, Hughes DA, Packard CJ, Caslake MJ: Hepatic production of vldl1 but not vldl2 is related to insulin resistance in normoglycaemic middle-aged subjects. Atherosclerosis 2004;176:49-56.

-41 Chen CH, Lu J, Chen SH, Huang RY, Yilmaz HR, Dong J, Elayda MA, Dixon RA, Yang CY: Effects of electronegative vldl on endothelium damage in metabolic syndrome. Diabetes care 2012;35:648-653.

-42 Gianturco SH, Bradley WA: Pathophysiology of triglyceride-rich lipoproteins in atherothrombosis: Cellular aspects. Clin Cardiol 1999;22:II7-14.

43 Rapp JH, Lespine A, Hamilton RL, Colyvas N, Chaumeton AH, Tweedie-Hardman J, Kotite L, Kunitake ST, Havel RJ, Kane JP: Triglyceride-rich lipoproteins isolated by selected-affinity anti-apolipoprotein b immunosorption from human atherosclerotic plaque. Arterioscler Thromb 1994;14:1767-1774. 